\title{
BÉRIOU, Nicole, JOSSERAND, Philippe (coord.), Prier et Combattre - Dictionnaire européen des ordres militaires au Moyen Âge
}

João Costa

\section{(2) OpenEdition}

\section{Journals}

Edição electrónica

URL: http://journals.openedition.org/medievalista/238

DOI: 10.4000/medievalista.238

ISSN: 1646-740X

Editora

Instituto de Estudos Medievais - FCSH-UNL

\section{Refêrencia eletrónica}

João Costa, «BÉRIOU, Nicole, JOSSERAND, Philippe (coord.), Prier et Combattre - Dictionnaire européen des ordres militaires au Moyen Âge », Medievalista [Online], 10 | 2011, posto online no dia 01 julho 2011, consultado o 22 setembro 2020. URL : http://journals.openedition.org/medievalista/238 ; DOI : https://doi.org/10.4000/medievalista.238

\section{(c) (†) (8)}

Mediavalista está licenciado com uma Licença Creative Commons - Atribuição-NãoComercial 4.0 Internacional. 
Título: Recensão

BÉRIOU, Nicole, JOSSERAND, Philippe (coord.), Prier et Combattre Dictionnaire européen des ordres militaires au Moyen Âge, Fayard, 2009. Autor(es): João Costa

Enquadramento Institucional: Membro do Centro de Estudos Históricos, FCSH-UNL

Contacto: jtscosta86@gmail.com

Fonte: Medievalista [Em linha]. №10, (Julho 2011). Direc. José Mattoso. Lisboa: IEM.

Disponível em: http://www2.fcsh.unl.pt/iem/medievalista/

ISSN: $1646-740 \mathrm{X}$

\section{Recensão}

BÉRIOU, Nicole, JOSSERAND, Philippe (coord.), Prier et Combattre -

Dictionnaire européen des ordres militaires au Moyen Âge, Fayard, 2009.

\section{João Costa}

Os investigadores dedicados ao estudo das Ordens Religiosas e Militares terão, finalmente, encontrado a sua "Bíblia". Tal como aqueles ligados à História Económica e Social e, mais tarde, à História das Mentalidades tinham nos homens e metodologias dos Annales a sua linha-mestra, também agora a historiografia em torno das Ordens conta com um instrumento de trabalho absolutamente fundamental no desenvolver da investigação nesta área de estudos.

Este projecto teve o seu início em 2003, desenrolando-se até 2007 e culminando numa publicação final dois anos mais tarde. Com base num trabalho interdisciplinar e 
plurinacional, com o contributo de 230 autores - entre outros, Philippe Josserand e Nicole Bériou, Carlos de Ayala Martínez, Damien Carraz, Alain Demurger, Helen Nicholson, Alan Forey, Kristjan Toomaspoeg, François-Olivier Touati, Pierre-Vincent Claverie, ou Luís Filipe Oliveira, Isabel Cristina Fernandes, Paula Pinto Costa e Cristina Pimenta, no caso português - espalhados por 25 nações, sob coordenação de Nicole Bériou e Philippe Josserand, dois nomes indeléveis na investigação em redor das Ordens, foi dado à estampa este dicionário que contém mais de 1100 entradas, umas mais desenvolvidas do que outras, mas sempre procurando tocar os múltiplos aspectos referentes à vida destas instituições.

Compor um dicionário relativo à investigação científica, nomeadamente no âmbito das ciências sociais e humanas, comporta sempre alguns riscos. Nomeadamente o equilíbrio conseguido ao nível da profundidade e da riqueza dos conteúdos, bem como dos enfoques adoptados. Neste sentido, a própria pluralidade de origem dos textos, somada à variedade de línguas em que, inicialmente, foram redigidos, obrigaram, seguramente, a um esforço acrescido de coordenação editorial.

Aliás, um dos principais atributos desta obra encontra-se, precisamente, na uniformidade do seu conjunto. Mercê do trabalho de coordenação de Nicole Bériou e de Philippe Josserand, e em articulação com os coordenadores nacionais deste projecto em Portugal, a Dr. ${ }^{a}$ Isabel Cristina Fernandes -, culminando num processo sistemático de tradução dos textos, conseguiu-se atingir uma muito positiva uniformização formal e, mais importante, conceptual. Como afirma Anthony Luttrell na introdução que redigiu sobre esta obra, o presente volume é fundamental na definição de questões técnicas e de terminologias em torno do estudo das Ordens ${ }^{1}$.

Um obstáculo que tem sido colocado à evolução dos estudos nesta área é a dificuldade de acesso que muitos investigadores têm em relação à historiografia produzida na Europa Central, em países como a Alemanha, e, principalmente, na Europa de Leste, mercê do escasso domínio, nos países da Europa Ocidental, das línguas em que são redigidos muitos desses textos.

\footnotetext{
${ }^{1}$ LUTTRELL, Anthony, Prier et Combattre - Dictionnaire européen des ordres militaires au Moyen Âge, coord. Nicole Bériou, Philippe Josserand, Fayard, 2009, p. 15.
}

Medievalista online $N^{\circ} 10 \mid$ Julho - Dezembro 2011 ๑ IEM - Instituto de Estudos Medievais 2 www2.fcsh.unl.pt/iem/medievalista 
Esta obra vem, portanto, ajudar a contornar este problema e facultar a um maior número de investigadores o acesso a uma extensa bibliografia - como seja a relativa aos cavaleiros Teutónicos - cujas temáticas, objectos de estudo e conceitos eram, até agora, de mais difícil acesso. A padronização das entradas do dicionário em língua francesa e a disponibilização, para cada uma delas, de bibliografia relativa ao tema em causa permitem que muitos leitores possam contactar com temas e conteúdos que, na sua maioria, eram pouco conhecidos para muitos deles.

Por outro lado, os coordenadores científicos desta obra procuraram romper com algumas barreiras institucionais ainda existentes na investigação histórica e convidar especialistas de outras áreas científicas para participar neste projecto. São essenciais os contributos conceptuais e de conteúdos trazidos pela História da Arte e pela Arquitectura - nomeadamente nos temas relativos à arte e arquitectura religiosa e castelar das Ordens -, mas também pelos Estudos Literários e pela Arquivística sublinhe-se o interesse dedicado às bibliotecas conventuais, para cuja importância do estudo alertou recentemente o professor José Mattoso ${ }^{2}-$, e, claro está, a Arqueologia que tem permitido romper as barreiras e limites com que o trabalho do historiador, tout court, se depara - e mesmo pelo Cinema, relativamente aos usos por esta indústria das temáticas relacionadas com as Ordens, e em que as Cruzadas têm merecido um claro destaque.

Mas, como em todas as obras, no sentido literal do termo, também nesta existem alguns pontos que poderiam ser melhorados.

Ao nível da organização interna e de conteúdos, mais especificamente das temáticas em torno da administração e recursos destas instituições, parece-nos existir uma certa redundância na abordagem destes temas. Apesar de em cada entrada deste dicionário se pretender dar uma visão abrangente que englobe todas, ou quase todas, as instituições relacionadas, o que impõe algumas restrições e cuidados ao nível do uso de terminologias e de conceitos que diferem, muitas vezes, de Ordem para Ordem, a verdade é que os assuntos de cariz económico e de exploração de recursos se encontram divididos por vários apartados - "comenda", "propriedade fundiária", "economia",

\footnotetext{
2 MATTOSO, José, "A vida religiosa e espiritual nas Ordens Militares", in Ordens Militares e Religiosidade - Homenagem ao professor José Mattoso, Palmela, GEsOS/Câmara Municipal de Palmela, 2010, pp. 11-21.
}

Medievalísta online $\mathrm{N}^{\circ}$ 10| Julho - Dezembro 2011 @ IEM - Instituto de Estudos Medievais 3 www2.fcsh.unl.pt/iem/medievalista 
"comércio", etc. - quando muitas vezes poderiam ter sido aglomerados num só texto que uniformizasse a informação e que assim evitasse alguma repetição e a dispersão do leitor por múltiplas entradas.

Por outro lado, Anthony Luttrell alerta-nos para o facto de este volume se ater ao período medieval, o que pode constituir um elemento redutor da visão que se transmite ${ }^{3}$. No entanto, há que ponderar os conceitos de "medievalidade" e de "modernidade" e as suas balizas cronológicas, sempre tão voláteis consoante o tema em discussão, bem como a necessidade de padronizar conceitos distintos em relação a cada época. É claro que uma cronologia mais vasta teria consequências na dimensão e no prazo de execução deste projecto ${ }^{4}$.

À margem dos conteúdos e da inegável qualidade do livro, não podemos deixar de assinalar o que consideramos ser a exorbitância do preço fixado pela editora Fayard. Os quase $200 €$ são um exagero para um livro deste tipo. Esta situação reveste-se de maior estranheza quando se verifica que os próprios organizadores da obra a destinam também a ser adquirida pelo grande público. Será, sem dúvida, por causa do preço que, até à data, nenhuma instituição bibliotecária portuguesa adquiriu um exemplar que coloque ao dispor dos leitores...

Apesar destes pequenos reparos, o cômputo geral é claramente positivo.

A investigação em torno das Ordens tem-se assumido um crescente volume de produção mas também uma maior qualidade científica na sua abordagem das últimas décadas. A riqueza arquivística dos fundos destas instituições e o reposicionar do investigador em função do seu objecto de estudo, actualizando os inquéritos a colocar às fontes - sejam elas em suporte escrito de papel, pergaminho ou velino, ou epigráfico, ou de edificado, etc. - permitem um alargar do campo epistemológico do investigador. Daqui tem resultado uma multiplicação de teses académicas, artigos, publicações de fontes, organização de encontros científicos e mesmo criação revistas especializadas nestes temas, de que um dos mais recentes resultados é a edição deste mesmo dicionário.

\footnotetext{
${ }^{3}$ LUTTRELL, Anthony, Prier et Combattre - Dictionnaire européen des ordres militaires au Moyen Âge, coord. Nicole Bériou, Philippe Josserand, Fayard, 2009, p. 16.

${ }^{4}$ Não deixa, contudo, de nos parecer interessante e fundamental, para uma perspectiva integrada destas temáticas na média e na longa durações, que fosse dado à estampa um segundo volume que abordasse cronologias grosso modo compreendidas entre o século XVI e o XIX.
} 
A sua organização interna, alfabética, claro está, pode agrupar-se em várias temáticas; entre as mais relevantes, temos:

- orgânica e administração institucional das Ordens;

- organização económica das Ordens;

- vida quotidiana das Ordens (e em seu redor);

- normativa das Ordens: regras, estatutos, definições;

- personalidades destacadas de cada instituição;

- monarcas e Santos Padres;

- religiosidade e espiritualidade;

- guerra: batalhas, instrumentos e técnicas bélicos;

Muitos apartados temáticos são acompanhados de imagens e cartografia, que ajudam a contextualizar a questão e que facilitam a apreensão do conteúdo dos textos.

De leitura obrigatória será a introdução historiográfica inicial, de autoria de Alain Demurger ${ }^{5}$. O autor faz uma panorâmica da abordagem historiográfica ao estudo das Ordens desde princípios do século XVI até ao século XXI. A noção dos conceitos e das perspectivas que se foi tendo destes temas, bem como a percepção de que não há métodos nem conceptualizações esgotados, e a sugestão de temáticas ainda, em boa medida, por explorar, mas que já deram contributos importantes - religiosidade e espiritualidade das Ordens, prosopografia dos seus membros, a perspectiva laica sobre as Ordens inseridas na comunidades locais, etc. -, são um bom alicerce para o investigador, nomeadamente para aqueles que começam agora a percorrer os "caminhos das Ordens".

Por fim, poder-se-ia colocar a seguinte questão: será este dicionário um ponto de partida ou um ponto de chegada? Muitas vezes o tom de alguns dos textos parece-nos limitador de qualquer progresso futuro sobre esse tema. Contudo, em termos gerais,

\footnotetext{
${ }^{5}$ DEMURGER, Alain, "Histoire de l'historiographie des ordres religieux-militaires de 1500 à nos jours", in Prier et Combattre - Dictionnaire européen des ordres militaires au Moyen Âge, coord. Nicole Bériou, Philippe Josserand, Fayard, 2009, pp. 22-46.
}

Medievalista online №10| Julho - Dezembro 2011 @ IEM - Instituto de Estudos Medievais 5 www2.fcsh.unl.pt/iem/medievalista 
fundamentalmente pela introdução historiográfica a que anteriormente aludimos, e pela leitura integrada e comparativa dos textos relativos a Portugal e dos respeitantes a outras paragens, nomeadamente os de produção ibérica, pensamos, para o caso português, que esta obra significará um ponto de partida privilegiado para a evolução da historiografia nacional sobre as Ordens religioso-militares. Poderemos não possuir algumas das fontes documentais existentes noutros países, mas os modelos e os conceitos que esta obra nos apresenta são transversais e caber-nos-á aproveitar esses contributos e dar-lhes o uso devido.

Para terminar, pensamos também que este será um passo fundamental para uma ainda maior discussão internacional e para a aferição de métodos, perspectivas e conceitos em torno destas temáticas, podendo, futuramente, culminar numa actualização deste dicionário, ajudando a confirmar ou reformular ideias e a criar novos objectos de análise.

Mas não antecipemos o futuro. Para já, saúde-se esta obra que será, para o presente e para os anos vindouros, uma referência incontornável e de leitura obrigatória para o investigador das Ordens Militares.

\section{COMO CITAR ESTE ARTIGO}

\section{Referência electrónica:}

COSTA, João - Recensão "BÉRIOU, Nicole, JOSSERAND, Philippe (coord.), Prier et Combattre - Dictionnaire européen des ordres militaires au Moyen Âge, Fayard, 2009.. Medievalista [Em linha]. №10, (Julho de 2011). [Consultado dd.mm.aaaa]. Disponível em http://www2.fcsh.unl.pt/iem/medievalista/MEDIEVALISTA10lcosta1008.html. ISSN 1646-740X. 
Recensão • João Costa

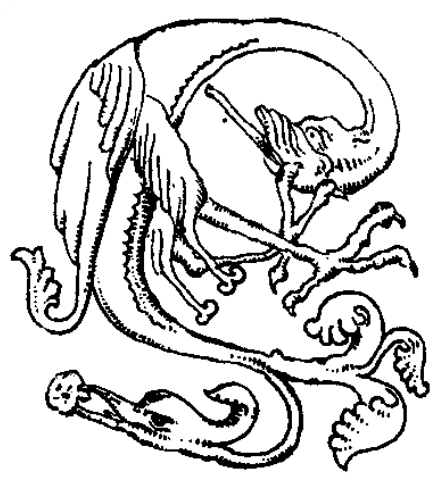

